\title{
Assimetrias de gênero e indignidade na sucessão hereditária
}

\author{
Cibele Cheron' (iD) 0000-0003-3501-5248 \\ Guilherme Wünsch ${ }^{2}$ (iD) 0000-0003-4668-3735 \\ 'Instituto Federal de Educação, Ciência e Tecnologia do Rio Grande do Sul, Viamão, \\ RS, Brasil. 94440-000 \\ 2Universidade do Vale do Rio dos Sinos, São Leopoldo, RS, Brasil. 93020-190.
}

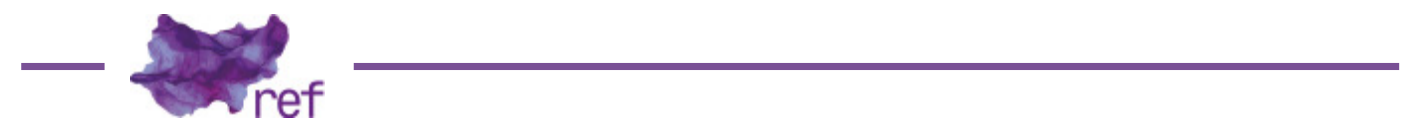

Resumo: Parte-se da noção de gênero, concebido como percepções sobre diferenças entre os sexos que culminam na construção de desiguais significados culturais e posições na hierarquia social atribuídos a mulheres e homens para analisar a Indignidade no Direito Sucessório. A pesquisa é bibliográfica, documental, de caráter exploratório e descritivo, empregando abordagem qualitativa. Sustenta-se que, ante as profundas assimetrias de gênero que marcam sociedades patriarcais, grande parte dos dispositivos legais taxativos, da sorte do Artigo 1.814 do Código Civil Brasileiro, expõe a normatividade de situações em que os grupos sociais hegemônicos têm consagrada sua proteção, em detrimento do restante do corpo social.

Palavras-chave: relações de gênero; Direito das Sucessões; indignidade; mulheres; violência..

Gender asymmetries and indignity in hereditary succession

Abstract: This study analyzes the figure of Indignity, in the Brazilian Inheritance Law, by the focus of gender relations. It begins with the notion of gender, conceived as perceptions about the differences between the sexes that culminate in the construction of different cultural meanings attributed to women and men, to which are associated different and hierarchical social positions. The research carried out is bibliographical and documentary, exploratory and descriptive, using qualitative approach. It is argued that, in view of the reality of deep gender inequalities that mark patriarchal societies, a large part of the statutory legal provisions, like the Article 1,814 of the Civil Code, expose the normativity of situations in which hegemonic social groups assure their protection, in detriment of the society as a whole. Key words: Gender Relations; Inheritance Law; Indignity; Women; Violence

\section{Considerações iniciais}

Embora as relações de poder não sejam compreensíveis unicamente pelo âmbito do Direito, é impossível ignorar que tal universo é transpassado por relações de poder e disputas de interesses, a despeito de sua pretensa neutralidade. Esse esforço de neutralidade, inefetivo, anuvia as disputas próprias de um campo de poder, acarretando opacidade ao processo político e conflitivo que o constitui. Nesse campo, estar sob a proteção do ordenamento significa ter vencido uma disputa. Dessa forma, a tutela jurídica do Estado Democrático de Direito demanda negociações, preponderantemente entre atores e atrizes sociais cujas participações não têm a mesma relevância na formulação de leis, dada a assimetria no exercício de poder e representação de seus interesses (Jünger HABERMAS, 1997). Possuir determinados atributos e/ou pertencer a dados grupos resulta, a priori, em desfrutar de condições de exercício de poder, possibilitando vencer as disputas que resultam na proteção do Estado, concretizada pela tutela jurídica.

Nas sociedades modernas, o Direito reconhece protagonismo a um sujeito abstrato, concebido em favor de uma igualdade formal que desconsidera o gênero, a raça/etnia, a classe 
e os demais atributos fundantes da desigualdade social. A pretensa neutralidade adotada pelo Direito não abrange as realidades das e dos sujeitos, fragmentada e móvel, que situa as mulheres "como entes abstratos, titulares de igualdade formal, não obstante agraciadas por diversos dispositivos legais que lhes asseguram direitos que carecem, muitas vezes, de qualquer efetividade" (Heloisa BARBOZA; Vitor ALMEIDA JUNIOR, 2017, p. 243). Ao visibilizar as circunstâncias que corporificam a existência das e dos sujeitos, transitando-se da abstração do "sujeito de direito" para a realidade, é impossível ignorar o sistema de relações no qual as pessoas se constroem e se desenvolvem (Débora FIGUEIREDO, 1997).

A lógica da modernidade concebe o mundo a partir de dualismos: abstrato/concreto, universal/particular, objetivo/subjetivo, cultural/natural, racional/irracional, ativo/passivo. Segundo Frances Olsen (2000), os polos desses dualismos são sexualizados e hierarquizados, atribuindo-se superioridade aos correspondentes à masculinidade e inferioridade aos correspondentes à feminilidade. O Direito, definido como sistema de normas racionais, abstratas e universais, é identificado ao polo masculino.

Ainda que a "justiça" seja representada como uma mulher, segundo a ideologia dominante o direito é masculino e não feminino. O direito é supostamente racional, objetivo, abstrato e universal, assim como os homens consideram a si mesmos. Pelo contrário, assume-se que o direito não é irracional, subjetivo ou pessoal, assim como os homens consideram que as mulheres sejam' (OLSEN, 2000, p. 26 [grifo da autora] [Tradução livre]).

Importa salientar que outras categorias, tais quais raça/etnia e classe/trabalho, articulamse ao gênero, condicionando status desiguais nas estruturas das sociedades. $O$ padrão de dominação funde identidades étnico/raciais às hierarquias, contribuindo para a inferiorização e a manutenção da condição de subalternidade de mulheres negras, indígenas, lésbicas, transexuais e/ou pobres como criaturas sem fala e sem poder. As categorias gênero, raça/etnia e classe/trabalho são indissociáveis para a análise de sociedades patriarcais, que tradicionalmente estabelecem explorações embasadas na oposição dicotômica entre sujeito e objeto. O sujeito é personificado pelo homem, branco, adulto, proprietário e patriarca, padrão cultural, econômico e político, ativo produtor do conhecimento, da riqueza, das leis e das decisões. Por sua vez, o objeto é corporificado numa construção irreal e monolítica - "a mulher" -, que precisa ser tutelada, pois é incapaz da práxis política, e também representada, pois não sabe falar por si (Gayatri SPIVAK, 2012; Karina BIDASECA, 2011). À margem do sistema normativo, situações de submissão e dependência das mulheres em relação aos homens reforçam o poder patriarcal nas famílias, assentado numa subordinação análoga ao escravismo (Neuma AGUIAR, 2000).

Com a Modernidade, a sociedade civil estabelece uma ordem social fundada no patriarcado fraternal dos homens, cidadãos, que exercem seu poder sobre as mulheres, excluídas da condição de indivíduo. Os homens nascem livres e iguais e transformam essa liberdade natural na segurança da liberdade civil, protegida através da afirmação jurídica de direitos. Pela diferença sexual, as mulheres são alijadas da igualdade legal, bem como da liberdade civil (Carole PATEMAN, 1993). Nesse diapasão, as assimetrias de gênero são produzidas e reproduzidas, conforme constata Alessandro Baratta (1999):

Para compreender o mecanismo geral de reprodução do status quo da nossa sociedade, contemporaneamente patriarcal e capitalista, faz-se necessário ter presente não apenas a importância estrutural da separação entre esfera pública e privada, mas também, da complementariedade dos mecanismos de controle próprios dos dois círculos. Em um corpo social como o nosso, a divisão entre público e privado, formal informal, constitui um instrumento material e ideológico fundamental para o funcionamento de uma economia geral do poder, na qual todas as várias relações de domínio encontram o seu alimento específico e, ao mesmo tempo, se entrelaçam e sustentam (p. 48).

Ante a realidade de profundas desigualdades de gênero que marcam sociedades patriarcais, como a brasileira, grande parte dos dispositivos legais taxativos, da sorte do art. 1.814, CC/2002, expõe a normatividade de situações em que grupos sociais hegemônicos têm consagrada sua proteção, em detrimento do restante do corpo social. Propõe-se, nesse marco, analisar criticamente a indignidade, no Direito Sucessório, tendo em conta o gênero, concebido como percepções de diferenças entre os sexos que culminam na construção de significados culturais e espaços na hierarquia social desigualmente atribuídos a mulheres e homens, que dá significado a relações de poder (Joan SCOT, 1995). Para tal, a pesquisa realizada é bibliográfica, documental, de caráter exploratório e descritivo, empregando abordagem qualitativa a fim de favorecer o debate num campo ainda aberto, que requer a atenção de estudantes e profissionais do Direito.

\footnotetext{
'Texto original: "Aunque la 'justicia' sea representada como una mujer, según la ideología dominante el derecho es masculino y no femenino. Se supone que el derecho es racional, objetivo, abstracto y universal, tal como los hombres se consideran a sí mismos. Por el contrario, se supone que el derecho no es irracional, subjetivo o personalizado, tal como los hombres consideran que son las mujeres" (OLSEN, 2000, p. 26).
} 


\section{Um Direlto neutro? Discriminação, violência contra as mulheres e feminicídio}

Composto de discursos e práticas masculinistas, o Direito legitima a opressão dos homens sobre as mulheres. Assim, ao reivindicar a proteção da lei, as mulheres se deparam com um sistema já estabelecido do ponto de vista masculino, no qual a aplicação da norma abstrata significa a concretização da perspectiva dos homens. Ao provocar a função jurisdicional do Estado, aciona-se a dominação masculina, uma vez que o "Estado de Direito liberal é o domínio dos homens sob o disfarce do Estado de Direito - seu poder é intensificado através da hegemonia do subterfúgio" (Wayne MORRISON, 2006, p. 585).

A representação formal do Direito o pressupõe como um sistema, racionalmente elaborado, completo, coerente, unívoco, interpretado e aplicado com neutralidade e imparcialidade. No entanto, superando a representação formal do campo jurídico e evidenciando sua sexualização e hierarquização, vê-se emergir um Direito pleno de indeterminações, inconsistências e ambiguidades, palpáveis em textos discriminatórios, categorias estereotipadas e interpretações enviesadas. A representação formal do Direito implica, assim, a ausência de regulação da esfera privada, perpassada por assimetrias de poder. Nos espaços domésticos, a prática reiterada das mais diversas formas de violências contra mulheres exemplifica o patriarcalismo característico das sociedades modernas.

A violência contra mulheres foi reconhecida pela Organização Mundial de Saúde (Etienne KRUG; Linda DAHLBERG; James MERCY; Anthony ZWl; Rafael LOZANO, 2002) como problema de saúde pública, identificado a partir de quaisquer atos que resultem em sofrimentos e danos psicológicos, físicos e sexuais, consumados ou sob a forma de ameaças, bem como coerção ou privação da liberdade, tanto na vida privada quanto na pública. Atos de violência contra mulheres ocorrem continuamente, e aumentam progressivamente de gravidade e intensidade, podendo culminar em homicídio.

Segundo o Fórum Brasileiro de Segurança Pública (FBSP, 2017a), em 2016 foram contabilizados 4.606 Crimes Violentos Letais Intencionais (CVLI), que somam ocorrências de homicídio doloso, latrocínio e lesão corporal seguida de morte praticadas contra mulheres, perfazendo $3,9 \%$ a menos do registrado em 2015. Embora os registros tenham diminuído entre 2015 e 2016, o percentual de feminicídios incluídos nesses registros aumentou. Em 2015, os feminicídios correspondiam a 9,4\% dos CVLI, aumentando para 13,5\% em 2016.

O Portal de Notícias G1, em parceria com o Núcleo de Estudos da Violência da Universidade de São Paulo e o FBSP, divulgou levantamento indicando registro, em 2015, de 3.777 homicídios dolosos com vítimas do sexo feminino, equivalentes a 3,6 mortes a cada cem mil mulheres. Dessas mortes, cerca de $13 \%$ foram registradas como feminicídios. Em 2016, os registros de homicídios com vítimas do sexo feminino aumentaram para 4.201 , elevando a taxa para 4 mortes a cada cem mil mulheres. O percentual de feminicídios registrados no ano foi 19,3\%. Também em 2017 os registros de homicídios dolosos contra mulheres aumentaram, alcançando 4.473 casos e 4,3 mortes a cada cem mil mulheres. Os feminicídios equivaleram a $21,1 \%$ dos registros ${ }^{2}$ (Clara VELASCO; Gabriela CAESAR; Thiago REIS, 2018).

Entende-se por feminicídios os homicídios praticados contra mulheres que derivem de qualquer manifestação ou exercício de relações desiguais de poder entre homens e mulheres, nos quais estas são mortas pela simples condição de ser mulher. Mormente, são cometidos por homens respaldados pela desigualdade de gênero, contando com a complacência social e das autoridades instituídas. Ocorrem nas mais diversas situações, abarcando mortes executadas por parceiros ou ex-parceiros íntimos, crimes seriais, episódios de violência sexual seguidos de morte, extermínio de mulheres, entre outras possíveis. São precedidos por amplo leque de agressões físicas, psicológicas, patrimoniais e sexuais, tais quais estupro, tortura, prostituição forçada, privação de liberdade, isolamento, tráfico humano, assédio moral e sexual (Ana CARCEDO, 2010).

Chama atenção a dificuldade de se obter dados referentes às mortes de mulheres por circunstâncias da violência doméstica e feminicídios. Em março de 2018, a Organização Não Governamental Artigo 19 divulgou resultados de pesquisa encomendada ao Instituto Datafolha e FBSP:

Segundo o Mapa de Violência 2015, o número de assassinatos chega a 4,8 para cada 100 mil mulheres. O mesmo Mapa aponta que, entre 1980 e 2013, 106.093 pessoas morreram por serem mulheres. O Dossiê Feminicídio destaca que no ano de 2010 se registravam 5 espancamentos a cada 2 minutos, em 2013 já se observava 1 feminicídio a cada 90 minutos e, em 2015, o serviço de denúncia Ligue 180 registrou 179 relatos de agressão por dia (ARTIGO 19, 2018, p. 2).

\footnotetext{
${ }^{2}$ Em 2015, 11 Estados brasileiros não registraram dados acerca do feminicídio: Amapá, Bahia, Ceará, Espírito Santo, Maranhão, Mato Grosso, Paraná, Pernambuco, Rio de Janeiro, Rondônia e Sergipe. Em 2016, Bahia, Maranhão, Mato Grosso, Rondônia e Sergipe não registraram dados, e Tocantins apresentou apenas dados parciais. Em 2015, Ceará, Mato Grosso e Rondônia não registraram dados, e Minas Gerais, Paraíba e Tocantins apresentaram apenas dados parciais.
} 
A pesquisa destaca que "os dados disponibilizados podem não ser os mais necessários, não estar devidamente atualizados, inviabilizar cruzamentos essenciais, não ser apresentados em linguagem ou formato adequados ou, simplesmente, conter sérios erros oriundos da produção e coleta" (ARTIGO 19, 2018, p. 2). Referentes aos mesmos períodos e bases territoriais, são encontrados números distintos para ocorrências iguais. Contudo, a infraestrutura nacional demonstra problemas de processamento e gerenciamento das informações.

Sabe-se que os dados são subestimados. Não há, por exemplo, estimativa nacional oficial sobre a quantidade de mulheres assassinadas por parceiros. Samira Bueno e Juliana Martins (2018) indicam que registros do sistema de saúde sobre mortes por agressão contabilizam que $50 \%$ das mulheres vítimas de homicídio morreram pelas mãos de familiares, sendo que $33 \%$ destes foram o marido ou o companheiro. O próprio Sistema de Informações sobre Mortalidade (SIM) do Ministério da Saúde reconhece que a cobertura dos registros não alcança a totalidade das mortes, aferindo que cerca de $7 \%$ dos óbitos ocorridos não estão registrados. Dos casos registrados, não foi possível indicar as causas de um em cada 14. Ainda, importa salientar que parte das mortes ocorridas por violências é classificada como "eventos cuja intenção é indeterminada" (Leila Posenato GARCIA; Lúcia Rolim FREITAS; Gabriela Drummond SILVA; Doroteia HÖFELMANN, 2013, p. 5).

Embora o combate à violência contra as mulheres tenha ganhado visibilidade e enfrentamento a partir da Lei Maria da Penha, n. ${ }^{\circ} 1$ 1.340/2006 (BRASIL, 2006), no Brasil, apenas em março de 2015 foi sancionada a Lei $n^{\circ} 13.104 / 2015$ (BRASIL, 2015), tipificando o feminicídio conforme as Conclusões Acordadas da 7a Sessão da Comissão sobre o Status da Mulher da Organização das Nações Unidas, que exige medidas para "reforçar a legislação nacional, onde [seja] apropriado, para punir assassinatos violentos (gender-related) e integrar mecanismos ou políticas específicas para prevenir, investigar e erradicar essas deploráveis formas de violência de gênero" (BRASIL, 2013, p. 1004). Com essa lei, o feminicídio foi reconhecido como homicídio qualificado e incluído no rol dos crimes hediondos.

Alguns elementos se destacam quanto ao feminicídio: a) vítima mulher, em função de o patriarcado construir a subalternidade e a vulnerabilidade sobre a identidade de gênero feminina; b) práticas cometidas contra o corpo da mulher, evidentes em mutilações, maus-tratos, geralmente não percebidos quando se trata de crime cometido contra homem; c) expectativa de impunidade, presente na culpabilização social da vítima, no questionamento de sua conduta e nas ofensas de natureza moral; d) relação pessoal existente entre vítima e algoz, normalmente familiar, afetiva ou de confiança, como atuais ou ex-esposos, companheiros, namorados, amantes, pais, filhos; e) existência de antecedentes ou informações de ameaças, perseguição ou assédio do algoz para com a vítima; f) indícios de que o crime tenha ocorrido por vingança associada a fato anterior; g) exposição pública do corpo, necrofilia ou pós-vitimização (CARCEDO, 2010).

A falta de registro adequado de feminicídios pode ser tributada à naturalização da violência contra mulheres, aceita pela sociedade e replicada pelas instituições (violência estrutural e institucional). É comum ver o tratamento dispensado ao feminicídio como crime passional, produto de ciúmes, ou tentativa de atenuar a ação do feminicida atribuindo-lhe conduta mediante paixão incontrolável. A existência do próprio termo delito passional permite ao feminicida pleitear descaracterização de suas reais intenções, mascarando o dolo, diante de uma sociedade adestrada a entender os crimes perpetrados contra mulheres como normais, mesma linha interpretativa das instituições policiais e jurídicas. Embora o panorama brasileiro seja severo, a proteção da lei é insuficiente quando se trata de feminicídio ou de homicídio de mulheres em circunstâncias de violência doméstica, realidades minimizadas no debate político e jurídico (VELASCO et al., 2018).

A violência contra as mulheres também tem lugar nas discriminações praticadas nas esferas política, econômica, social, cultural, civil e institucional, contemplando as cometidas pelo Estado e seus agentes, como é o caso da falta de diligência nas investigações policiais e na desídia do Judiciário na punição dos criminosos (Haydée ILLUECA, 2012). A Lei Maria da Penha, art. $7^{\circ}$, II, define a violência psicológica praticada contra a mulher como qualquer conduta que lhe cause dano emocional, diminuição da autoestima, prejuízo do pleno desenvolvimento, que vise a degradar ou controlar suas ações, comportamentos, crenças ou decisões, ante ameaça, constrangimento, humilhação, manipulação, isolamento, vigilância constante, perseguição contumaz, insulto, chantagem, ridicularização, exploração ou limitação da autodeterminação ou da saúde psicológica. Adentra, aqui, a definição de honra das mulheres de forma a visibilizar que atitudes coercitivas causam prejuízos insanáveis neste aspecto (Maria Berenice DIAS, 2007).

A Secretaria de Políticas para as Mulheres do Governo Federal publicou em 2015 o resultado de dez anos de funcionamento da Central de Atendimento à Mulher - Ligue 180. Dos 4.708.978 atendimentos, $11,7 \%$ referiram-se a relatos de violência cometida contra mulheres. Desses relatos, $27,74 \%$ corresponderam a casos de violência psicológica (BRASIL, 2016). Em 2016, 12,4\% dos atendimentos corresponderam a relatos de violência, sendo $31,8 \%$ referentes à violência psicológica (BRASIL, 2017). 
Sabe-se que as agressões não comportam apenas palavrões lançados de forma esporádica, mas ataques cotidianos à saúde mental e à dignidade das mulheres, em reiterados episódios de violência psicológica que as nulifica. Nesses ataques os agressores estabelecem não a mera ofensa, mas o sequestro da subjetividade das vítimas, reiterando a dominação patriarcal. Assim, torna-se imprescindível a releitura da compreensão acerca dos crimes contra a honra das mulheres, a partir da noção de violência psicológica introduzida pela Lei Maria da Penha.

Fato é que a honra das mulheres sempre foi tratada, na sociedade e pelo arcabouço institucional, de forma diferente da dos homens. Por esse atributo, entende-se que a pessoa honrada é merecedora de admiração e respeitabilidade, figurando altivamente entre os membros de dada comunidade. A modernização do país foi construída sobre a ótica da honra sexual, submetendo as mulheres à virgindade física e moral, e a intervenção do Estado em prol da manutenção de uma ordem social assentada nas diferenças: de gênero, de classe, de etnia (Sueann CAULFIELD, 2000).

Para protegê-las, o Estado e a sociedade exigem das mulheres a conduta compreendida como correta: casta, voltada aos valores familiares tradicionais, maternal. A replicação desses valores é de tal forma naturalizada na sociedade que legitima a tese de dominação patriarcal, introjetando nas próprias mulheres as condicionantes para conceberem-se como pessoas de honra (PATEMAN, 1993). Enquanto a honra masculina é baseada na habilidade de manter a reputação de virilidade, de coragem e de provedor do lar, a feminina vem ligada à sexualidade contida, moral elevada e dedicação integral à família, infligindo às mulheres uma disciplina incessante (Pierre BOURDIEU, 2010). Não raro se vê a sociedade questionar o direito de reparação das mulheres por dano sofrido quanto à honra em razão de seu comportamento não corresponder às imagens culturalmente projetadas. Também não raro as mulheres deixam de reportar ou exigir reparações a agravos cometidos contra sua honra por conta da antevista exposição negativa, acompanhada de julgamento da opinião pública, mesmo quando são vítimas.

As raízes históricas da violência cometida contra mulheres têm correlação estreita com o processo de colonização e subalternização de grupos sociais, em função do gênero, da raça/ etnia, da orientação sexual e dos estereótipos construídos. Analisando tais categorias em perspectiva interseccional, percebe-se que as assimetrias e a discriminação são potencializadas, como observa Kimberlé Crenshaw (2002):

Há um reconhecimento crescente de que o tratamento simultâneo das várias 'diferenças' que caracterizam os problemas e dificuldades de diferentes grupos de mulheres pode operar no sentido de obscurecer ou de negar a proteção aos direitos humanos que todas as mulheres deveriam ter. Assim como é verdadeiro o fato de que todas as mulheres estão, de algum modo, sujeitas ao peso da discriminação de gênero, também é verdade que outros fatores relacionados a suas identidades sociais, tais como classe, casta, raça, cor, etnia, religião, origem nacional e orientação sexual, são 'diferenças que fazem diferença' na forma como vários grupos de mulheres vivenciam a discriminação. Tais elementos diferenciais podem criar problemas e vulnerabilidades exclusivos de subgrupos específicos de mulheres, ou que afetem desproporcionalmente apenas algumas mulheres (p. 173 [grifo da autora]).

Em relação ao gênero, os valores morais difundidos por esse processo e o conservadorismo da sociedade contribuíram para legitimar uma violência histórica contra mulheres, negros(as), povos originais e homossexuais, por exemplo. No Brasil, a violência contra esses grupos ganhou nova dimensão com a propagação dos meios virtuais, especialmente ao se considerar "acontecimentos recentes do contexto brasileiro que por um lado evidenciam tanto uma onda de conservadorismo com amplo poder de mobilização nas redes, como uma ampliação de leis e projetos de lei que prezam por aumento da vigilância no contexto online" (CODING RIGHTS; INTERNETLAB, 2017, p. 10). O FBSP (2017b) identificou o ambiente virtual - especialmente as redes sociais - como espaço de práticas violentas contra mulheres, destacando-se que cerca de $1 \%$ das mulheres identificou a internet como local onde, nos últimos 12 meses, haviam sofrido a violência considerada mais grave.

Com o objetivo de coibir as práticas violentas contra mulheres em ambiente virtual, foi sancionada, em abril de 2018, a Lei n. ${ }^{\circ} 13.642$ (BRASIL, 2018), conhecida como Lei Lola, alterando a Lei $n^{\circ} 10.446 / 2002$, atribuindo à Polícia Federal a investigação de crimes ocorridos através da rede mundial de computadores que difundam conteúdo misógino, tais quais os cometidos contra a ativista do movimento feminista e professora da Universidade Federal do Ceará, Dolores (Lola) Aronovich Aguero. Lola, que empresta o nome à lei, sofreu ameaças e ataques virtuais em 2017 , mas a polícia estadual não foi capaz de identificar os autores dos crimes.

Sublinha-se que a violência contra mulheres praticada em ambiente virtual é difícil de ser caracterizada, assim como a maior parte das violências calcadas no gênero. Grande parte das práticas que constituem violência não é reconhecida como tal, banalizada, nesse caso, pela crença de que iniciam e se esgotam no meio virtual, não gerando maiores repercussões na vida da vítima. A culpabilização das vítimas também é outro fator de banalização, somada "a questões 
de acesso à justiça, à falta de sensibilização de agentes de law enforcement desde o momento da denúncia até as deliberações do judiciário, e à falta de adequação das políticas das plataformas (CODING RIGHTS; INTERNETLAB, 2017, p. 15).

A prática de violência contra as mulheres é tida, de forma geral, como resultado de um sistema ideológico de dominação masculina, produzido e reproduzido por homens e mulheres. Compreende ações que convertem diferenças em desigualdades e assimetrias hierarquicamente postas, para dominação, exploração, opressão. Através dessas ações, o dominante trata a dominada não como sujeito, mas como objeto, tornando-a silente, dependente e passiva. A mulher em situação de violência, objeto de dominação, perde sua autonomia, ou seja, sua liberdade, sua capacidade de autodeterminar-se para pensar, sentir, querer e agir (Marilena CHAUI, 1984). Nessa concepção, a mulher é reduzida a um ser dependente e subalterno, cuja liberdade foi tolhida sistematicamente ao longo de um processo de isolamento e agressões continuadas, nem sempre físicas. A dominação masculina adentra o campo do simbólico, como aponta Bourdieu (2010):

A força da ordem masculina pode ser aferida pelo fato de que ela não precisa de justificação:
a visão androcêntrica se impõe como neutra e não tem necessidade de se enunciar, visando
sua legitimação. A ordem social funciona como uma imensa máquina simbólica, tendendo a
ratificar a dominação masculina na qual se funda: é a divisão social do trabalho, distribuição
muito restrita das atividades atribuídas a cada um dos dois sexos, de seu lugar, seu momento,
seus instrumentos... (p. 15).

Assim, a própria sujeição da mulher pelo homem já consiste numa forma de violência, que se institui por meio da adesão forçosa da dominada, uma vez que ela não dispõe de meios para pensar a relação com o dominador senão enquanto algo natural, tão incorporada no seu âmbito de vida que define sua existência social. Numa sociedade de bases patriarcais, a dominação do homem sobre a mulher é tolerada e naturalizada, situando-se e gerando efeitos nos campos político, ideológico e econômico. O sistema ideológico machista socializa o homem para dominar e submeter a mulher, atribuindo-lhe a prerrogativa de praticar atos violentos contra ela (Heleieth SAFFIOTI; Suely ALMEIDA, 1995).

Diferente da violência física, a violência psicológica não deixa marcas aparentes, sendo mais difícil de detectá-le e comprová-la. Ela pode ser definida por toda ação que a mulher sofre sob a forma de agressões verbais, repetitivas, humilhações, ameaças, culpabilizações, abusos, intimidação, isolamento e desprezo, que normalmente têm lugar no ambiente doméstico e familiar. Fazem parte de um crescente de eliminação da autonomia da mulher.

Fundamental destacar que, inúmeras vezes, vítimas de violência psicológica não visualizam o que lhes acomete como suficientemente grave para agirem em sua própria defesa, ou denunciar o agressor aos órgãos competentes. Grande parte das vítimas sequer considera ser levada a sério, caso denunciasse. Em outra relevante parcela dos casos, as mulheres são orientadas a permanecerem nas situações de abuso em função da família, do casamento e dos valores tradicionais. Tendo como ponto de partida que o Direito não é neutro quanto ao gênero, a raça/ etnia, a classe/trabalho, à orientação sexual e a tantas outras características das e dos sujeitos, busca-se analisar alguns dos principais aspectos da norma brasileira acerca da indignidade sucessória que implicam a desigual proteção a homens e mulheres, em desfavor destas. Com esse fito, é observada a configuração da indignidade: no que consiste, quando e como ocorre, a quem atinge, questionando-se os entendimentos dos(as) principais autores(as) do Direito de Sucessões.

\section{A indignidade no ordenamento brasileiro: disciplina, controvérsias e a necessidade de um olhar mais acurado}

No ordenamento jurídico brasileiro, a definição clássica da indignidade, cunhada por Clóvis Beviláqua (2000), ensina tratar-se de "privação do direito hereditário cominada por lei a quem cometeu certos atos à pessoa ou aos interesses do hereditando"3 (p. 120). Ou seja, a indignidade é uma punição aplicada a quem tenha ofendido gravemente a pessoa de quem sejam herdeiros(as) ou legatários(as). A prática dos atos ofensivos, descrita na lei, é de tal forma gravosa, que se torna incompatível com o recebimento de bens ou benefícios provenientes da herança, punindo-se o(a) indigno(a) com a impossibilidade de recebê-los.

\footnotetext{
${ }^{3}$ No presente estudo, buscou-se adotar linguagem inclusiva quanto ao gênero. Todavia, nas citações diretas, foi mantida a linguagem empregada por autoras e autores que mormente empregam o masculino como elemento de universalização da linguagem. Entendemos a linguagem, em suas múltiplas expressões, passível de um uso sexista que dissemina e intensifica as assimetrias e hierarquias estabelecidas nas relações sociais em função da valorização desigual do masculino e do feminino, em detrimento deste. Para maiores aprofundamentos, sugerimos a leitura de Débora de Carvalho Figueiredo (1997).
} 
Atinge, portanto, quem seja potencialmente favorecido pela herança. ${ }^{4}$

Todavia, em situações previstas na lei, algumas pessoas restam excluídas do recebimento do quinhão hereditário. Assinala-se que a sucessão é amparada pelo afeto, real ou presumido, da pessoa autora da herança por quem sucedê-la. Com base no afeto, se espera gratidão das e dos sucessores para com a pessoa falecida, ou, no mínimo, respeito à vontade expressa por ela. O herdeiro ou a herdeira se tornam indignos ao praticar determinados atos que evidenciam desrespeito e desestima à pessoa falecida, violando o afeto constituinte. Assim, a indignidade intenta punição civil pela perda dos benefícios decorrentes da sucessão (Sebastião AMORIM, 2004).

O Código Civil (BRASIL, 2002) traz as hipóteses em que a indignidade pode ser configurada, dispostas nos incisos do art. 1.814:

Art. 1.814. São excluídos da sucessão os herdeiros ou legatários:

I - que houverem sido autores, coautores ou partícipes de homicídio doloso, ou tentativa deste, contra a pessoa de cuja sucessão se tratar, seu cônjuge, companheiro, ascendente ou descendente;

II - que houverem acusado caluniosamente em juízo o autor da herança ou incorrerem em crime contra a sua honra, ou de seu cônjuge ou companheiro;

III - que, por violência ou meios fraudulentos, inibirem ou obstarem o autor da herança de dispor livremente de seus bens por ato de última vontade (BRASIL, 2002).

Para autoras e autores dogmáticos do campo jurídico, esse rol é taxativo, ou seja, elenca todas as possibilidades de configuração da indignidade. Considerada uma penalidade civil, não comporta a possibilidade de interpretação extensiva ou analógica, uma vez que não se admite punição sem prévia cominação legal (Maria Helena DINIZ, 2010). Ainda em atenção ao seu caráter punitivo, a indignidade só se configura quando o Poder Judiciário a declara, em decisão quanto ao mérito de ação judicial específica, que poderá ser ajuizada por quem tenha interesse na sucessão ou pelo Ministério Público (legitimado conforme a Lei n. ${ }^{\circ}$ 13.532/2017).

Dias (2013) reitera: "ainda que o agir do herdeiro tenha sido indigno e mesmo que o testador tenha deserdado, a inércia para a propositura da ação simplesmente faz desaparecer as causas de exclusão e o herdeiro é contemplado com o seu quinhão hereditário, como se nada tivesse feito de errado" (p. 299). Assim, a observância do texto legal vigente condiciona a indignidade à decisão judicial na Ação Declaratória de Indignidade. Esse condicionamento é questionado pelo Projeto de Lei (PL) n. ${ }^{\circ} 7.806$ de 2010 (BRASIL, 2010), que objetiva sanar a possibilidade de a falta de provocação da jurisdição beneficiar a pessoa indigna, determinando que a condenação daquele(a) que houver praticado os crimes referidos no artigo 1.814 (CC/ 2002), em ação penal transitada em julgado, automaticamente cause sua exclusão da condição de herdeiro(a) ou legatário(a). ${ }^{5}$

Todavia, tal proposta encontra resistência entre reconhecidos(as) autores(as) do Direito de Sucessões, cujo argumento se sustenta na separação entre as esferas cível e criminal, na jurisdição brasileira. Por essa lógica, os efeitos da condenação penal não se estendem ao juízo cível, sendo que "indigno é o que comete o fato e não quem sofre a condenação penal" (Cristiano de FARIAS; Nelson ROSENVALD, 2015, p. 115). Argumentam, igualmente, que a individualização da ofensa, característica do juízo criminal, não se aplica às relações regidas pelo Direito Civil, no qual vigora o princípio da solidariedade (Paulo LÔBO, 2014). Pablo Gagliano e Rodolfo Pamplona Filho (2015) ressalvam a possibilidade de, posteriormente, a sentença penal absolutória negar a autoria ou a materialidade do fato imputado ao(à) indigno(a), recomendando que se aguarde o deslinde criminal para declarar a indignidade.

A desnecessidade de prévia condenação penal é ponto pacífico para as e os autores, quando o ato cometido pelo(a) indigno(a) se enquadra na previsão do inciso I do art. 1.814, ou seja, em caso de homicídio tentado ou consumado. Algumas considerações se fazem necessárias, todavia, quando tais atos são cometidos contra mulheres. Diferentemente da violência letal que vitima os homens, mais frequentemente ocorrida em espaços públicos, os crimes cometidos contra as mulheres mormente ocorrem em âmbito privado, praticados por aqueles com quem a vítima possui relação íntima, o que explicita e reforça a dominação patriarcal (GARCIA et al., 2013). Marcela Lagarde y de los Rios (2007), observando as particularidades que distinguem o feminicídio do homicídio, destaca o continuum de práticas violentas perpetradas contra mulheres e que têm no espaço doméstico um locus privilegiado:

\footnotetext{
${ }^{4}$ Conforme o Código Civil Brasileiro (CC/2002), morrendo a pessoa sem deixar testamento, transmitem-se seus bens aos herdeiros legítimos, expressamente indicados (art. 1.829) consoante a ordem de vocação hereditária. Em princípio, havendo parentesco até o quarto grau, há o direito de suceder. Embora as disposições sucessórias sejam complexas, dada a multiplicidade das relações familiares, a regra para suceder é, no momento da abertura da sucessão, estar vivo e ter o parentesco exigido por lei (art. 1.798).

${ }^{5}$ Em maio de 2018 o referido PL aguardava designação de relatoria na Câmara dos Deputados.
} 
A violência de gênero é a violência misógina contra as mulheres pelo fato de serem mulheres, situadas em relações de desigualdade de gênero: opressão, exclusão, subordinação, discriminação, exploração e marginalização. As mulheres são vítimas de ameaças, agressões, maus-tratos, lesões e danos misóginos. As modalidades de violência de gênero são: familiar, na comunidade, institucional e feminicida (LAGARDE Y DE LOS RIOS, 2007, p. 33).

Nesse sentido, Jane Caputi e Diana Russel (1992) apontam que o feminicídio é o fim de uma longa e variada trajetória de abusos que resultam na morte de mulheres, constituindo o extremo de um modelo sistêmico, universal e estrutural de violências que se fundam no poder patriarcal. Para Lagarde y de los Rios (2007), o feminicídio ocorre em cenários de impunidade, omissão, negligência e conivência das autoridades do Estado e da estrutura social. Assim, o feminicídio se desdobra em violência interpessoal, estrutural e institucional, revelando a complexidade das vulnerabilidades que atingem as mulheres. A par disso, sustenta-se que exigir prévia condenação criminal para que a indignidade possa ser efetivada significa favorecer o feminicida.

De forma diversa ao posicionamento unificado que ocorre quanto às previsões do inciso $\mathrm{I}, \mathrm{e}$ mesmo no tocante à denunciação caluniosa, também objeto do inciso ll do art. 1.814, há divergência teórica com relação à imprescindibilidade de prévia sentença condenatória por crime contra a honra, dada expressa menção à incorrência em crime. Segundo Francisco Cahali e Giselda Hironaka (2012), nesta situação específica seria necessária a condenação criminal preexistente. Por sua vez, Lôbo (2014) pondera que, caso o(a) ofensor(a) se retrate categoricamente da calúnia ou difamação, a norma penal admite isenção da pena, sem vincular "o juízo cível, que pode decidir pela exclusão da herança do ofensor, em virtude de sua natureza de reprovação moral" (p. 117).

Novamente, as assimetrias de gênero que transversalizam a estrutura social determinam que a exigência da condenação criminal seja ponderada. A ofensa à honra das mulheres é indissociável da violência moral, enquanto expressão da violência de gênero, normalizada de forma a consolidar o sistema hierárquico de poder assentado em assimetrias de gênero. Rita Segato (2003) considera que a violência moral é o embrião de todas as demais formas da violência de gênero, acontecendo, inclusive, através de gestos, olhares e posturas, muitas vezes sem ofensa verbal explícita. O reconhecimento da violência moral contra as mulheres encontra barreiras na naturalização das dinâmicas de dominação patriarcal que impregnam as relações familiares e interpessoais. Por conta disso, tanto a sociedade quanto o Estado tratam como naturais, normais e exclusivas da esfera privada condutas ofensivas à honra feminina, tais quais a humilhação, ridicularização, desqualificação, intimidação e desvalorização das mulheres em suas capacidades cognitivas, profissionais e emocionais, de seus corpos, comportamentos e identidades. Nesse patamar, afirma-se que condicionar a efetivação da indignidade à prévia condenação criminal novamente importa em benefício ao(à) ofensor(a).

Ainda quanto à abrangência da indignidade, ressalta-se que os efeitos da exclusão sucessória são pessoais. Assim, na sucessão da pessoa autora da herança, os(as) descendentes do(a) excluído(a) o(a) sucedem por representação. Cabe salientar que a indignidade se adstringe à matéria de Direito das Sucessões. A norma brasileira determina a exclusão do(a) indigno(a) da herança, mas não da meação. O direito à meação significa a atribuição de bens a cada cônjuge. Quando da dissolução da sociedade conjugal, seja por divórcio, morte ou demais causas aventadas na lei, o patrimônio será dividido apenas para designar a cada um a pertença dos bens que the incumbem. Todavia, pela norma em vigor, o(a) cônjuge é herdeiro(a) necessário, sendo-Ihe garantida a legítima parte da herança (art. 1.845, CC/2002).

A interpretação literal do direito à meação pode ser fonte de injustiça quando as circunstâncias do caso concreto não são colocadas em perspectiva, apreciando-se meramente se o(a) indigno(a) é herdeiro(a) ou meeiro(a). A possibilidade de o(a) indigno(a) ter acesso à meação unicamente através do cometimento do homicídio da pessoa autora da herança não é sopesada.

Quanto à efetividade, a indignidade começa a surtir efeitos a partir do trânsito em julgado da sentença que a declara. $O(a)$ indigno(a) devolverá frutos e rendimentos havidos a partir da herança, pois é considerado(a) possuidor(a) de má-fé frente os(as) demais herdeiros(as), desde a abertura da sucessão (art. 1.817, CC/2002). Consoante o art. 1.818, CC/2002, o(a) indigno(a) poderá ser reabilitado(a), se a pessoa ofendida neste sentido se houver manifestado, inequívoca e irretratavelmente, em ato autêntico ou testamento (Carlos Roberto GONÇALVES, 2010).

Também nesse aspecto é imperativo avaliar o conteúdo da norma sob o prisma de gênero. A reabilitação do(a) indigno(a) mediante o perdão da pessoa autora da herança pode ser interpretada como o que Lourdes Maria Bandeira (2014) denomina de "armadilhas e táticas do poder patriarcal, na medida em que a existência das mulheres é carregada de sentidos: ser esposa, mãe, filha, cuidadora, entre os compromissos de ser fiel, companheira, amiga, boa mãe, dentre outros" (p. 458). Essas chamadas armadilhas designam às mulheres a imposição de relativizar as ofensas sofridas em nome da unidade familiar, da conservação do matrimônio, da pacificação das relações, do bem-estar dos filhos e de outros valores que a sociedade coloca acima da honra feminina subjetivamente referida. 
Os aspectos da indignidade apresentados são objeto de divergências de posicionamentos da jurisprudência e de autoras e autores do campo jurídico. Nesse contexto, alterações no texto legislativo são aventadas, destacando-se o PL n. ${ }^{\circ} 867$, de 2011 (BRASIL, 201 1), que propõe ampliar as hipóteses de impedimento de sucessão por indignidade mantendo a essencialidade de caracterização de conduta dolosa, mas incluindo, entre aqueles contra a conduta é dirigida, os parentes até segundo grau e demais pessoas com as quais o(a) de cujus mantenha laços de afinidade. ${ }^{\circ}$ A ampliação do PL n. ${ }^{\circ} 867 / 2011$ dispensa a condenação criminal prévia e inclui atos atentatórios da integridade física, liberdade e patrimônio da pessoa autora da herança, reconhecendo-os como bens jurídicos tutelados. Também reduz o prazo para demandar exclusão de herdeiro(a) e transforma abandono e desamparo, hipóteses para deserdação na norma vigente, em causas de indignidade. Ainda, estende o impedimento para a sucessão àqueles(las) que incorrerem indiretamente nas hipóteses do art. 1.814, ampliando a proteção legal aos casos em que o(a) ofensor(a) do(a) de cujus não seja seu(sua) herdeiro(a) ou legatário(a), mas, em virtude de conexão com estes(as), possa ser beneficiário(a) da herança.

Todavia, ainda que discussões teóricas e jurisprudenciais sejam essenciais, e alterações importantes no tratamento da matéria sejam realizadas e propostas, resta uma grande falha no escopo protetivo da lei, em função da inobservância das questões inerentes ao gênero. Embora a indignidade exista para preservar a pessoa falecida, sua memória e sua vontade ante a possibilidade de seu(sua) ofensor(a) ser beneficiado(a) pela herança, o dispositivo normativo não tem o mesmo alcance para homens e mulheres. Importa considerar assimetrias condicionantes de uma hierarquia social que tem os homens no topo e, na base, as mulheres, resultando em mecanismos complexos de preconceito, discriminação e desvalorização cuja compreensão exige análise histórica e cultural (Waldir QUADROS, 2004). Assim, apesar da previsão legal, é possível que o(a) ofensor(a) seja beneficiado(a) pela herança, dado a lei não considerar a realidade de mulheres e homens a partir do sistema desigualitário socialmente construído.

O inciso I do art. 1.814 afasta dos benefícios advindos da herança quem tiver atentado contra a vida do(a) de cujus, seu(sua) descendente, ascendente, cônjuge ou companheiro(a), cometendo homicídio doloso, consumado ou tentado. A caracterização da intenção de matar é essencial, não abrangendo o que o Código Penal (BRASIL, 1940) caracteriza como error in persona, aberratio ictus, legítima defesa, estado de necessidade, exercício regular de direito, loucura ou embriaguez (art. $20, \S 3^{\circ}$, art. 23 , I a III; art. 26 e art. 28, II). O entendimento é de que, nesses casos, o ato lesivo não foi voluntário, ausente o dolo (GONÇALVES, 2010). Do prisma das relações de gênero, a hipótese do inciso I vindica olhar para as mortes de mulheres decorrentes de conflitos de gênero, a fim de fomentar uma análise mais focada da indignidade.

Não identificar as causas relativas às mortes de mulheres potencializa a descaracterização do dolo, elemento essencial para a declaração de indignidade, e o consequente afastamento do(a) agressor(a) do recolhimento da herança. Por conseguinte, o homicídio culposo - advindo de imprudência, negligência e imperícia - não implica indignidade, assim como aqueles em que for acatada tese de legítima defesa, exercício regular de direito, estado de necessidade, estado de insanidade mental e embriaguez.

Concernente ao inciso Il do art. 1.814 do CC/2002, resta excluído(a) de usufruir da herança por indignidade quem tiver atentado contra a honra da pessoa falecida. Tais atentados podem ocorrer, segundo a previsão legal, de duas formas: quando o(a) excluído(a) da herança tiver cometido o crime de denunciação caluniosa contra o(a) falecido(a), sabendo de sua inocência (art. 399, CP), ou quando praticar crime contra a honra do(a) falecido(a), seu(sua) cônjuge ou companheiro(a), configurando calúnia, difamação ou injúria (arts. 138 a 140, CP). Tais atos podem ter sido praticados durante a vida ou após a morte da pessoa autora da herança, devendo a lei proteger também sua memória.

A fim de que a hipótese de denunciação caluniosa gere efeitos sucessórios, a lei determina que a imputação do crime se dê em juízo, restringido pela doutrina para juízo criminal. Porém, dado que qualquer denúncia, em seara criminal ou cível, deva ser comunicada a membro do Ministério Público para regular requerimento e instauração de investigação, podendo incorrer em ação penal contra a pessoa denunciada, é necessário rever o entendimento predominante entre autores(as) do campo jurídico. O que a lei sucessória demanda é que o fato imputado à pessoa autora da herança seja crime do ponto de vista penal, e não que sua denúncia ocorra na seara penal (HIRONAKA, 2004).

A própria construção cultural da noção de honra inerente às mulheres é crucial para avaliar as condições de cabimento deste inciso quando, de fato, a honra feminina é atacada. Trazendo ao debate novamente a questão da honra feminina, enfatiza-se que, historicamente, as mulheres são divididas em três categorias: as honradas, as desonradas e as sem-honra, categorias que, embora flexibilizadas, ainda compõem o discurso que julga os comportamentos femininos para determinar

¿ O referido PL tramita na Câmara dos Deputados. Até maio de 2018, aguardava parecer do Relator da Comissão de Constituição e Justiça e de Cidadania (CCJC). 
quem é e quem não é de bem. Nosso modelo social patriarcal construiu um padrão de feminilidade que vincula diretamente a honra familiar à sexualidade feminina (Mary DEL PRIORE, 1993). A mulher não apenas deve ter ilibada honra pessoal, cujos patamares de definição são muito mais rígidos do que os do homem, mas também é guardiã da honra da família. A valoração positiva do masculino e negativa do feminino, neste ínterim, permite maior condescendência para com os comportamentos dos homens do que das mulheres, especialmente no campo sexual. Nesta senda, o simples fato de a pessoa autora da herança ser mulher pode ensejar a necessidade de um olhar mais aprofundado sobre o alcance do escopo protetivo pretendido pelo art. 1.814, I e II, CC/2002.

A última previsão legal para cabimento da indignidade trata dos casos em que o(a) de cujus desejasse atribuir legitimidade a outrem para participar da sucessão, incluindo novo(a) pessoa entre os beneficiados por sua herança, mas cujo herdeiro(a) ou legatário(a) pré-existente o(a) tenha impedido de manifestar tal vontade, empregando expedientes fraudulentos ou meios violentos. Trata-se de ofensa praticada exclusivamente contra a pessoa autora da herança, quando o(a) indigno(a) impede ou obsta a liberdade de dispor como bem quiser de seu patrimônio em manifestação de última vontade. Importa salientar que, em qualquer das condutas, para que se concretize a exclusão por indignidade, o ato de inibir ou obstar deverá ser praticado mediante o emprego de meio fraudulento ou violência, com ação física. Consoante à fraude, consiste em todo artifício malicioso despendido com a manifesta intenção de transgredir o Direito ou prejudicar a terceiros(as), iludindo-os(as), sem que haja um ato ostensivo de violação da lei (HIRONAKA, 2004).

Depreende-se que a norma jurídica objetive proteger a liberdade de testar da pessoa falecida, estabelecendo punição a quem, de forma dolosa, coercitiva, ou fraudulenta, a induza em erro substancial (DINIZ, 2010). Merece análise mais cuidadosa o preceito sobre o emprego de violência, manifestada, conforme determina o inciso, na forma de atos físicos. Tal como já mencionado, a Lei Maria da Penha inova ao introduzir no ordenamento pátrio a noção de violência psicológica, anteriormente aludida neste artigo. Vale lembrar que, no caso de denunciação caluniosa, se advier a absolvição do denunciante, não poderá ocorrer nenhuma penalidade no juízo cível (Arnaldo RIZZARDO, 2009). Não obstante, ao restringir os atos de violência à prática física como criadora de inibição ou óbice à vontade da pessoa, o dispositivo normativo deixa de contemplar as mulheres em situação de violência psicológica ou moral, flagrantemente tolhidas de sua autonomia e liberdade. De toda sorte, a violência contra as mulheres, por sua peculiaridade, deve ser encarada de forma mais atenta.

\section{Considerações finais}

Embora o advento da Lei Maria da Penha, da Lei do Feminicídio e da Lei Lola tenham propiciado grande visibilidade ao tema, a violência contra as mulheres e os abusos praticados contra elas continuam sendo um grave problema social no Brasil, apesar dos importantes frutos oriundos dos esforços dos movimentos de mulheres e feministas para ver reconhecida a titularidade de direitos das mulheres, sem vínculo jurídico com o pai ou o marido. Porém, ainda resta o desafio de transformar práticas sociais e redefinir noções culturalmente construídas para garantir a efetivação desses direitos, especialmente com relação ao combate de todas as formas de discriminação e violência.

Os diplomas legais, em sua maioria, tratam mulheres e homens de forma genérica e universalista. Desconsideram, assim, os contextos sociais e culturais em que o sujeito homem e o sujeito mulher são construídos, em relações de poder assimétricas e desiguais. Não reconhecer tais diferenças implica impregnar a lei de uma pretensa - e falsa - neutralidade, na qual aquele(a) que exerce seus direitos será invariavelmente quem ocupa, nas construções sociais, os lugares privilegiados. Assim, a lei serve aos interesses do homem, adulto, branco, de classe média, cristão, heterossexual. Centralizar a titularidade de direitos no padrão do homem médio invisibiliza grande parte da sociedade, e inviabiliza a efetividade dos direitos de cidadãos e cidadãs que não se enquadram no dito padrão.

É preciso, ante o exposto, analisar o Direito não como um ideal já concretizado, um fim em si, mas como uma ferramenta em permanente construção para a paz e a justiça sociais. Reconhecer as diferenças entre aqueles e aquelas que o ordenamento visa a proteger é indispensável para assegurar a efetividade do próprio ordenamento, sob o risco de, em contrário, perpetuar-se a crise de legitimidade normativa que atravessa as esferas do cotidiano e o ideário das instituições políticas e jurídicas.

Os(as) operadores(as) do Direito devem, portanto, buscar construir alternativas possíveis para o reconhecimento e efetivação dos direitos de cidadãos e cidadãs, reconhecidos(as) em suas diferenças, a fim de que o Estado cumpra o seu dever de garantir a oportunidade de viver segundo a noção de Bem Comum, criada e recriada, levando-os(as) e a seus interesses em conta. O Direito não é senão uma realidade social, produzida por atividades humanas através de relações que se estabelecem dentro de padrões sociais e culturais. Todavia, o Direito não é apenas um produto da realidade social, mas uma ferramenta dotada da capacidade de incidir sobre essa 
realidade, transformando-a. Este papel dual do ordenamento, de refletir e, simultaneamente, transformar a realidade, dá aos(às) seus(suas) operadores(as) a possibilidade de transformarem o contexto no qual se inserem, a partir de um projeto centrado no dever-ser, uma teoria ativa de estruturação para uma sociedade de bases mais justas e mais igualitárias.

Não é possível ao Direito ignorar as relações de poder que se estabelecem entre as pessoas, e que influenciam suas capacidades para a própria vida social, cultural, familiar, afetiva, econômica, laboral, e todas as demais formas de interação humana. O Direito não pode desconhecer que é o poder que organiza a Sociedade e lhe dá estrutura e feição, condicionando as e os sujeitos a atuarem segundo lógicas de dominação, submissão, necessidades e demandas que impactam inexoravelmente o alcance da tutela jurídica.

Neste estudo, procurou-se demonstrar que as mulheres, dada a peculiar condição social de construção de sua subjetividade, dentro do sistema ideológico de dominação do Patriarcado, não alcançam a mesma proteção jurídica que os homens ante a previsão normativa designada à exclusão de herdeiros(as) e legatários(as) por indignidade. Ainda que modificações propostas em Projetos de Lei possam atenuar a realidade de segregação em virtude do gênero, alude-se a uma circunstância, entre abundantes possíveis, em que a tutela protetiva da lei não se estende da mesma forma sobre mulheres e homens.

Em vista do que foi discutido, defende-se a necessidade de conceber a lei e o alcance de sua proteção para além da ótica falaciosa da neutralidade, visibilizando as e os sujeitos de direitos em suas diferenças e garantindo-lhes o pleno exercício de suas cidadanias, pluralmente concebidas e reconhecidas. Espera-se, assim, ter-se contribuído para a disseminação do debate e ampliação da visão sobre as vulnerabilidades do arcabouço legislativo frente às múltiplas e desiguais realidades sociais.

\section{Referências}

AGUIAR, Neuma. "Patriarcado, sociedade e patrimonialismo". Sociedade e Estado, Brasília, v. 15, n. 2, p. 303-330, jun./dez. 2000.

AMORIM, Sebastião Luiz. Código Civil Comentado. São Paulo: Atlas, 2004.

ARTIGO 19. Dados sobre feminicídio no Brasil - \#invisibilidademata. São Paulo: Article 19, 2018. Disponível em: http://twixar.me/Y3WK. Acesso em: 08/05/2018.

BANDEIRA, Lourdes Maria. "Violência de gênero: a construção de um campo teórico e de investigação". Sociedade e Estado, Brasília, v. 29, n. 2, p. 449-469, ago. 2014.

BARATTA, Alessandro. "O paradigma do gênero: da questão criminal à questão humana". In: CAMPOS, Carmen Hein de (Org.). Criminologia e feminismo. Porto Alegre: Sulina, 1999. p. 19-80.

BARBOZA, Heloisa; ALMEIDA JUNIOR, Vitor. "(Des)lgualdade de gênero: restrições à autonomia da mulher”. Pensar, Fortaleza, v. 22, n. 1, p. 240-271, jan./abr. 2017.

BEVILÁQUA, Clóvis. Direito das Sucessões. Campinas: RED Livros, 2000.

BIDASECA, Karina. "Mujeres blancas buscando salvar a las mujeres color café de los hombres color café. Reflexiones sobre desigualdad y colonialismo jurídico desde el feminismo poscolonial". In: BIDASECA Karina; LABA, Vanesa Vazquez. Feminismos y poscolonialidad. Descolonizando el feminismo desde y en América Latina. Buenos Aires: Godot, 201 1. p. 95-118.

BOURDIEU, Pierre. A dominação masculina. Rio de Janeiro: Bertrand Brasil, 2010.

BRASIL. Decreto-Lei n 2.848, de 07 de dezembro de 1940. Código Penal. Diário Oficial da União, Brasília, DF, Sessão 1 de 31/12/1940. p. 23911.

BRASIL. Lei no 10.406, de 10 de janeiro de 2002. Código Civil. Diário Oficial da União, Brasília, DF, Sessão 1 de 11/01/2002. p. 1.

BRASIL. Lei n 1 1.340, de 07 de agosto de 2006. Diário Oficial da União, Brasília, Sessão 1 de 08/08/ 2006. p. 1.

BRASIL. Lei n 13.104, de 09 de março de 2015. Diário Oficial da União, Brasília, Sessão 1 de 10/03/ 2015. p. 1.

BRASIL. Lei n 13.642, de 03 de abril de 2018. Diário Oficial da União, Brasília, Sessão 1 de 04/04/ 2018. p. 1. 
BRASIL. Balanço anual - 2016: Central de Atendimento à Mulher - Ligue 180. Secretaria Nacional de Políticas para as Mulheres. Brasília, Ministério dos Direitos Humanos, 2017. Disponível em: http:/ /twixar.me/C3WK. Acesso em 17/04/ 2018.

BRASIL. Secretaria Nacional de Políticas para as Mulheres. Balanço de uma década de conquistas: Central de Atendimento à Mulher - Ligue 180. Brasília, Ministério das Mulheres, da Igualdade Racial e dos Direitos Humanos, 2016. Disponível em http://twixar.me/pyWK. Acesso em 17/04/2018.

BRASIL. Congresso Federal. Projeto de Lei n. ${ }^{\circ}$ 7.806, de 30 de agosto de 2010. Disponível em http:/ /twixar.me/HyWK. Acesso em 10/05/2018.

BRASIL. Congresso Federal. Projeto de Lei $n .^{\circ} 867$, de 4 de abril de 2011 . Disponível em http:// twixar.me/KzWK. Acesso em 08/05/2018.

BRASIL. Comissão Parlamentar Mista de Inquérito. Relatório final. Brasília: Senado Federal, 2013.

BUENO, Samira; MARTINS, Juliana. "Nada a comemorar". Portal G1, São Paulo, 07/03/2018. Disponível em https://g1 .globo.com/monitor-da-violencia/noticia/nada-a-comemorar.ghtml. Acesso em 08/05/ 2018.

CAHALI, Francisco; HIRONAKA, Giselda. Direito das Sucessões. São Paulo: Revista dos Tribunais, 2012.

CAPUTI, Jane; RUSSEL, Diana. "Femicide: sexist terrorism against women”. In: CAPUTI, Jane; RUSSEL, Diana. Femicidio: la política de matar mujeres. Nueva York: Twayne, 1992.

CARCEDO, Ana. No olvidamos ni aceptamos: femicidio en Centro América, 2000-2006. San Jose: CEFEMINA, 2010.

CAULFIELD, Sueann. Em defesa da honra: moralidade, modernidade e nação no Rio de Janeiro (1918-1940). Campinas: EDUnicamp/Centro de Pesquisa em História Social da Cultura, 2000.

CHAUI, Marilena. "Participando do Debate sobre Mulher e Violência". In: FRANCHETTO, Bruna; CAVALCANTI, Maria Laura; HEILBORN, Maria Luiza (Orgs.). Perspectivas Antropológicas da Mulher. Rio de Janeiro: Zahar, 1984. p. 23-62.

CODING RIGHTS; INTERNETLAB. Violências de gênero na internet: diagnóstico, soluções e desafios. Contribuição conjunta do Brasil para a relatora especial da ONU sobre violência contra a mulher. São Paulo, 2017. Disponível em http://twixar.me/RSWK. Acesso em 17/04/2018.

CRENSHAW, Kimberlé. "Documento para o encontro de especialistas em aspectos da discriminação racial relativos ao gênero". Revista Estudos Feministas, Florianópolis, v. 10, n. 1, p. 171-188, jan. 2002.

DEL PRIORE, Mary. Ao sul do corpo: condição feminina, maternidades e mentalidades no Brasil Colônia. Rio de Janeiro: José Olympio, 1993.

DIAS, Maria Berenice. A Lei Maria da Penha na Justiça. São Paulo: Revista dos Tribunais, 2007.

DIAS, Maria Berenice. Manual das Sucessões. São Paulo: Revista dos Tribunais, 2013.

DINIZ, Maria Helena. Curso de Direito Civil Brasileiro, v. 6, 25. ed. São Paulo: Saraiva, 2010.

FARIAS, Cristiano Chaves de; ROSENVALD, Nelson. Curso de Direito Civil. São Paulo: Atlas, 2015. (v. 6 - Famílias)

FBSP. Anuário Brasileiro de Segurança Pública 2017. São Paulo: Fórum Brasileiro de Segurança Pública, 2017a. Disponível em http://twixar.me/QSWK. Acesso em 31/03/2018.

FBSP. Visível e invisível: a vitimização de mulheres no Brasil. São Paulo: Fórum Brasileiro de Segurança Pública, 201 7b. Disponível em http://twixar.me/HSWK. Acesso em 17/04/2018.

FIGUEIREDO, Débora de Carvalho. "Gênero e poder no discurso jurídico". Revista de Ciências Humanas, Florianópolis, v. 15, n. 21, p. 37-52, jan. 1997.

GAGLIANO, Pablo Stolze; PAMPLONA FILHO, Rodolfo. Novo curso de Direito Civil. São Paulo: Saraiva, 2015. (v. 6 - Direito de Família: as famílias em perspectiva constitucional) 
GARCIA, Leila Posenato; FREITAS, Lúcia Rolim; SILVA, Gabriela Drummond; HÖFELMANN, Doroteia. Violência contra a mulher: feminicídios no Brasil (Sum). São Paulo: Ipea, 201 3. Disponível em http:/ /twixar.me/mXWK. Acesso em 30/04/2018.

GONÇALVES, Carlos Roberto. Direito Civil Brasileiro: Direito das Sucessões. São Paulo: Saraiva, 2010.

HABERMAS, Jürgen. Direito e Democracia: entre facticidade e validade, v. Il. Rio de Janeiro: Tempo Brasileiro, 1997.

HIRONAKA, Giselda. "Deserdação e exclusão da sucessão". In: HIRONAKA, Giselda; PEREIRA, Rodrigo (Coords.). Direito das Sucessões e o Novo Código Civil. Belo Horizonte: Del Rey, 2004. p. 355-368.

ILLUECA, Haidée Méndez. "Contribuições ao debate sobre a tipificação e penalização do femicídio". In: Comité de America Latina y el Caribe para la Defesa de los Derechos de la Mujer - CLADEM. Contribuições ao debate sobre a tipificação penal do feminicídio/femicídio. Lima: CLADEM, 2012. p. 81-84. Disponível em http://twixar.me/DXWK. Acesso em 12/05/2018.

KRUG, Etienne; DAHLBERG, Linda; MERCY, James; ZWI, Anthony; LOZANO, Rafael (Eds.). Relatório mundial sobre violência e saúde. Genebra: Organização Mundial de Saúde, 2002. Disponível em encurtador.com.br/cK035. Acesso em 12/05/2018.

LAGARDE Y DE LOS RIOS, Marcela. "Por los derechos humanos de las mujeres: la Ley General de Acceso de las Mujeres a una vida libre de violencia". Revista Mexicana de Ciencias Políticas y Sociales, México, v. XLIX, n. 200, p. 143-165, ago. 2007.

LÔBO, Paulo. Direito Civil: sucessões. São Paulo: Saraiva, 2014.

MORRISON, Wayne. Filosofia do Direito: dos gregos ao pós-modernismo. São Paulo: Martins Fontes, 2006.

OLSEN, Frances. "El sexo del Derecho". In: RUIZ, Alicia (Org.). Identidad Feminina y Discurso Jurídico. Buenos Aires: Biblos, 2000. p. 25-42.

PATEMAN, Carole. O contrato sexual. Rio de Janeiro: Paz e Terra, 1993.

QUADROS, Waldir. "Gênero e raça na desigualdade social brasileira recente". Estudos Avançados, São Paulo, v. 18, n. 50, p. 95-117, abr. 2004.

RIZZARDO, Arnaldo. Direito das Sucessões. Rio de Janeiro: Forense, 2009.

SAFFIOTI, Heleieth; ALMEIDA, Suely. Violência de gênero: poder e impotência. Rio de Janeiro: Revinter, 1995.

SCOTT, Joan. "Gênero: uma categoria útil de análise histórica". Educação e Realidade, Porto Alegre, v. 20, n. 2, p. 71-99, jul./dez. 1995.

SEGATO, Rita Laura. Las estructuras elementales de la violencia: ensayos sobre género entre la Antropología, el Psicoanálisis y los Derechos Humanos. Bernal: Universidad de Quilmes, 2003.

SPIVAK, Gayatri Chakravorty. Pode o subalterno falar? Belo Horizonte: EDUFMG, 2012.

VELASCO, Clara; CAESAR, Gabriela; REIS, Thiago. "Cresce o n. ${ }^{\circ}$ de mulheres vítimas de homicídio no Brasil; dados de feminicídio são subnotificados". Monitor da violência. Portal G1, 07/03/2018. Disponível em https://g1 globo.com/monitor-da-violencia/noticia/cresce-n-de-mulheres-vitimas-dehomicidio-no-brasil-dados-de-feminicidio-sao-subnotificados.ghtml. Acesso em 10/05/2018.

Cibele Cheron (Cibele.Cheron@edu.pucrs.br) é pós-doutoranda em Educação (PUCRS). Doutora em Ciência Política pela Universidade Federal do Rio Grande do Sul (UFRGS). Mestre em Ciências Sociais pela Pontifícia Universidade Católica do Rio Grande do Sul (PUCRS). Bacharel em Ciências Jurídicas e Sociais (UFRGS). Pesquisadora associada ao Núcleo Interdisciplinar de Estudos sobre Mulher e Gênero (UFRGS). Professora do Instituto Federal de Educação, Ciência e Tecnologia do Rio Grande do Sul (IFRS), Campus Viamão.

Guilherme Wünsch (guilhermewuns@unisinos.br) é doutor em Direito pela Universidade do Vale do Rio dos Sinos - UNISINOS - com estágio pós-doutoral na Pontifícia Universidade Católica do Rio Grande do Sul-PUCRS. Professor do Mestrado Profissional em Direito da Empresa e dos Negócios da UNISINOS. Professor do Curso de Direito da UNISINOS. Advogado e Sócio do Escritório Rita Pavoni Advogados, em São Leopoldo, RS. 
COMO CITAR ESSE ARTIGO DE ACORDO COM AS NORMAS DA REVISTA

CHERON, Cibele; WÜNSCH, Guilherme. "Assimetrias de gênero e indignidade na sucessão hereditária". Revista Estudos Feministas, Florianópolis, v. 28, n. 1, e58569, 2020.

CONTRIBUIÇÃO DE AUTORIA

Cibele Cheron: concepção, desenho de pesquisa, elaboração do manuscrito, redação, discussão de resultados.

Guilherme Wünsch: discussão de resultados, revisão da redação.

\section{FINANCIAMENTO}

Não se aplica.

CONSENTIMENTO DE USO DE IMAGEM

Não se aplica.

APROVAÇÃO DE COMITÊ DE ÉTICA EM PESQUISA

Não se aplica.

CONFLITO DE INTERESSES

Não se aplica.

\section{LICENÇA DE USO}

Este artigo está licenciado sob a Licença Creative Commons CC-BY Internacional. Com essa licença você pode compartilhar, adaptar, criar para qualquer fim, desde que atribua a autoria da obra.

\section{HISTÓRICO}

Recebido em 09/08/2018

Reapresentado em 17/04/2019

Aprovado em 21/05/2019 